\title{
STUDI NUMERIK SEPARASI ALIRAN 3D AKIBAT PENAMBAHAN FFST PADA BIDANG TUMPU AIRFOIL ASIMETRI
}

\author{
Studi Kasus: Airfoil Asimetri British 9C7/22.5C50 \\ Ika Nurjannah ${ }^{1}$, Herman Sasongko $^{2}$, Heru Mirmanto ${ }^{3}$ \\ ${ }^{1}$ Jurusan Teknik Mesin, Universitas Negeri Surabaya \\ ${ }^{2,3}$ Jurusan Teknik Mesin, Institut Teknologi Sepuluh Nopember \\ IIkajannah@unesa.ac.id \\ 2herman@me.ITS. ac.id \\ 3samir@me.ITS.ac.id
}

\begin{abstract}
Abstrak - Separasi aliran sekunder (aliran 3D) merupakan bentuk kerugian aliran yang tidak bisa dihindari pada mesin-mesin turbo. Pada kompresor aksial separasi aliran 3D akibat adanya interaksi antara dua benda yang saling berdekatan yaitu pada blade boundary layer dengan casing-hub boundary layer. Akibat dari aliran sekunder menyebabkan penyumbatan aliran (blockage effect) sehingga menyebabkan tekanan pada kompresor menurun. Upaya reduksi aliran sekunder dilakukan melalui penambahan forward facing step turbulator (FFST) pada bidang tumpu. Penelitian ini dilakukan secara simulasi numerik dengan menggunakan bantuan software FLUENT 6.3.26. Parameter yang digunakan pada aliran free stream $\mathrm{Re}=1.64 \times 10^{5}$ dan Intensitas Turbulensi Tu $=0,3 \%$ untuk mengkaji perbandingan karakteristik aliran pada bidang tumpu airfoil asimetri British 9C7/22.5C50 akibat penambahan forward facing step turbulator (FFST) dan tanpa FFST dengan variasi AoA sebesar $0^{0}, 8^{0}, 12^{0}, 14^{0}$, 16 $6^{0}$. Hasil penelitian menyebutkan bahwa dengan akibat penambahan FFST mengakibatkan intensitas turbulensi aliran di dekat dinding menjadi momentum, akibatnya aliran lebih mampu mengatasi kerugian tekanan (adverse pressure) dan garis separasi lebih kebelakang yang mengakibatkan wake lebih kecil. Pada penambahan angel of attack diperoleh posisi saddle point lebih mengarah ke lower side serta attachment line tidak terinduksi oleh horseshoe vortex, sehingga aliran lebih mampu mengikuti kontur bodi, akibatnya curling flow lebih lemah dan wake lebih sempit serta blockage (energy loss) dapat di reduksi. Reduksi energi akibat separasi aliran 3D dengan penambahan FFST terefektif pada $a=8^{\circ}$ sebesar $7,36 \%$.
\end{abstract}

Kata Kunci-Separasi aliran 3D ; Forward Facing Step Turbulator (FFST); energy losses.

\begin{abstract}
Secondary flow separation (3D flow) is a form of flow loss that cannot be avoided in turbo engines In the axial compressor, 3D flow separation is due to the interaction between two objects that are close to each other, namely the blade boundary layer with the casing-hub boundary layer. The result of the secondary flow causes blockage of the flow which causes the pressure on the compressor to decrease. Efforts to reduce secondary flow are carried out by adding a FFST to endwall. This re se arch was conducted in a numerical simulation using FLUENT 6.3.26 software. The parameters used in the free stream flow $R e=1.64 \times 10^{5}$ and Turbulence Intensity $\mathrm{Tu}=0.3 \%$ to assess the comparison of the flow characteristics on the endwall of the British 9C7 / 22.5C50 asymmetric airfoil due to the addition of a FFST and without FFST with variations AoA of $0^{\circ}, 8^{0}, 12^{\circ}, 14^{0}, 16^{0}$. The research result states that the addition of FFST causes the intensity of turbulence to flow near the wall to become momentum, as a result, the flow is better able to overcome the adverse pressure and the separation line is more retarded which results in smaller wake. With the addition of the angel of attack, the saddle point position is more directed to the lower side and the attachment line is not induced by the horseshoe vortex, so that the flow is more able to follow the contours of the body, as a result the curling flow is weaker and the wake is narrower and the blockage (energy loss) can be reduced. The energy reduction due to $3 D$ flow separation with the addition of FFST is effective at $a=8{ }^{\circ}$ of $7.36 \%$.
\end{abstract}

Keywords-3D flow separation; Forward Facing Step Turbulator (FFST); energy losses.

\section{PENDAHULUAN}

Upaya peningkatan efisiensi pada mesin-mesin turbo saat ini terus berkembang. Berdasarkan teori, Terjadinya aliran sekunder (aliran 3D) pada kompresor aksial akibat adanya interaksi antara dua benda yang saling berdekatan yaitu pada blade boundary layer dengan casing-hub boundary layer, sehingga menyebabkan terjadinya vortisitas sekunder yang merupakan cikal bakal terjadinya aliran sekunder.

Akibat dari aliran sekunder menyebabkan penyumbatan pada aliran (blockage effect) sehingga menyebabkan tekanan pada kompresor menurun. Horlock dan Lakshminarayana [1] menyebutkan, bahwa penyumbang losses tertinggi pada kompresor aksial adalah aliran sekunder (aliran 3D), yaitu 
sebesar 50\% dari kerugian hidrolis total, kemudian kerugian energi akibat gesekan pada dinding annulus dan kerugian akibat bentuk atau profile yang masing-masing sebesar $30 \%$ dan $20 \%$.

Mirmanto dan Sasongko [2] melalui penambahan leading edge fairing terhadap profil NACA 0015, menyebutkan adanya penurunan intensitas horseshoe vortex. Namun penggunaan leading edge fairing kurang sesuai apabila diaplikasikan pada AoA yang tinggi karena dapat mempengaruhi perubahan posisi forward saddle point.

Mengacu pada efek yang ditimbulkan dari kerugian aliran sekunder, Abdulla, dkk [3] melalui penelitian secara eksperimen antara kombinasi profil NACA 65-015 dengan bidang tumpu, diperoleh hasil visualisasi aliran yang jelas dimana single horseshoe vortex bernilai tinggi setelah leading edge dan titik ketebalan maksimum.

Penelitian secara numerik terkait variasi angle of attack sebesar $4^{0}, 8^{0}, 12^{0}$ pada compresor cascade $9 \mathrm{C} 7 / 32.5 \mathrm{C} 50$ oleh Nugroho dan Ikhwan [4], diperoleh informasi bahwa dengan peningkatan angle of attack, mampu mempengaruhi sadle point semakin ke arah pressure side, produksi turbulent kinetic energy meningkat, serta turbulent dissipation rate membesar.

Sherry, dkk [5] dengan penggunaan forward facing step turbulator (FFST), Diketahui bahwa penggunaan FFST mampu meningkatkan profil kecepatan yang signifikan pada water tunnel, sedangkan pada wind tunnel penggunaan FFST kurang terlihat.

Penelitian terkait penggunaan FFST pada airfoil diantaranya Mirmanto, dkk [6] pada NACA 0015 diperoleh informasi bahwa dengan penggunaan FFST dapat meningkatkan intensitas turbulen aliran di daerah dekat dinding. Penelitian selanjutnya Nurjannah, dkk [7] akibat penambahan FFST pada airfoil asimetri diketahui terjadi peningkatan intensitas turbulensi yang signifikan di daerah endwall junction sehingga mampu mereduksi energy loss.
Selanjutnya, Rohmawati, dkk [8] penelitian terkait penggunaan FFST pada airfoil asimetri asimetri british 9C7/42.5C50 menunjukkan hasil peningkatan Intensitas turbulensi akibat penambahan FFST, serta akibat penambahan angle of attack membuat berkurangnya Reduksi energy losses.

Oleh karena pentingnya kajian terkait cara mereduksi separasi aliran 3D, maka perlu dilakukan sebuah penelitian terkait penggunaan FFST pada airfoil asimetri british 9C7/22.5C50 dengan penambahan FFST secara simulasi numeric menggunakan variasi angle of attack $(\alpha)$ sebesar $0^{0}$, $8^{0}, 12^{0}, 14^{0}, 16^{0}$ untuk mengurangi terjadinya separasi aliran $3 \mathrm{D}$ sangat penting untuk dilakukan.

\section{METODE}

Metode penelitian secara simulasi numeric dengan software FLUENT 6.3.26, parameter yang digunakan pada aliran free stream $\operatorname{Re}=1.64 \times 10^{5}$ dan Intensitas Turbulensi $\mathrm{Tu}=0,3 \%$. Posisi FFST diletakkan pada posisi $\mathrm{L} / \mathrm{C}=2 / 3$ yang mengacu pada Mirmanto, dkk [6]. Selain itu model Viscous yang digunakan k-epsilonStandart, Persamaan turbulen yang digunakan berupa SIMPLEC, dan turbulent dissipation rate berupa 2nd order upwind. Meshing menggunakan quadrilateral atau hexahedron dengan nilai error 0.5 .

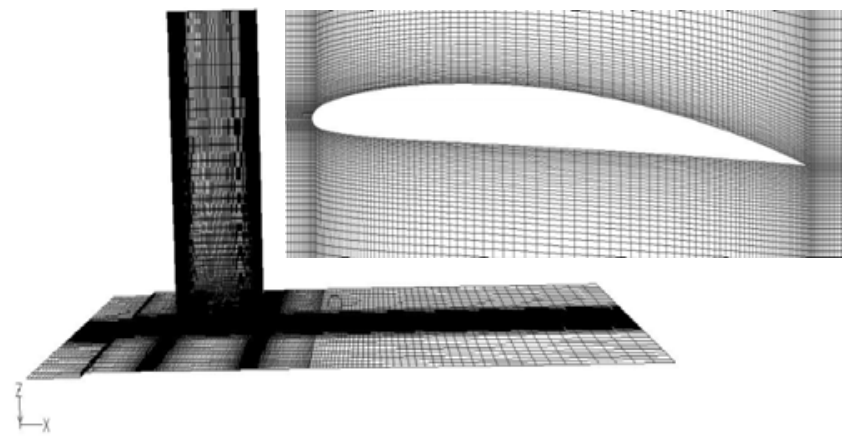

Gbr 2. Geometry MeshingGbr 2

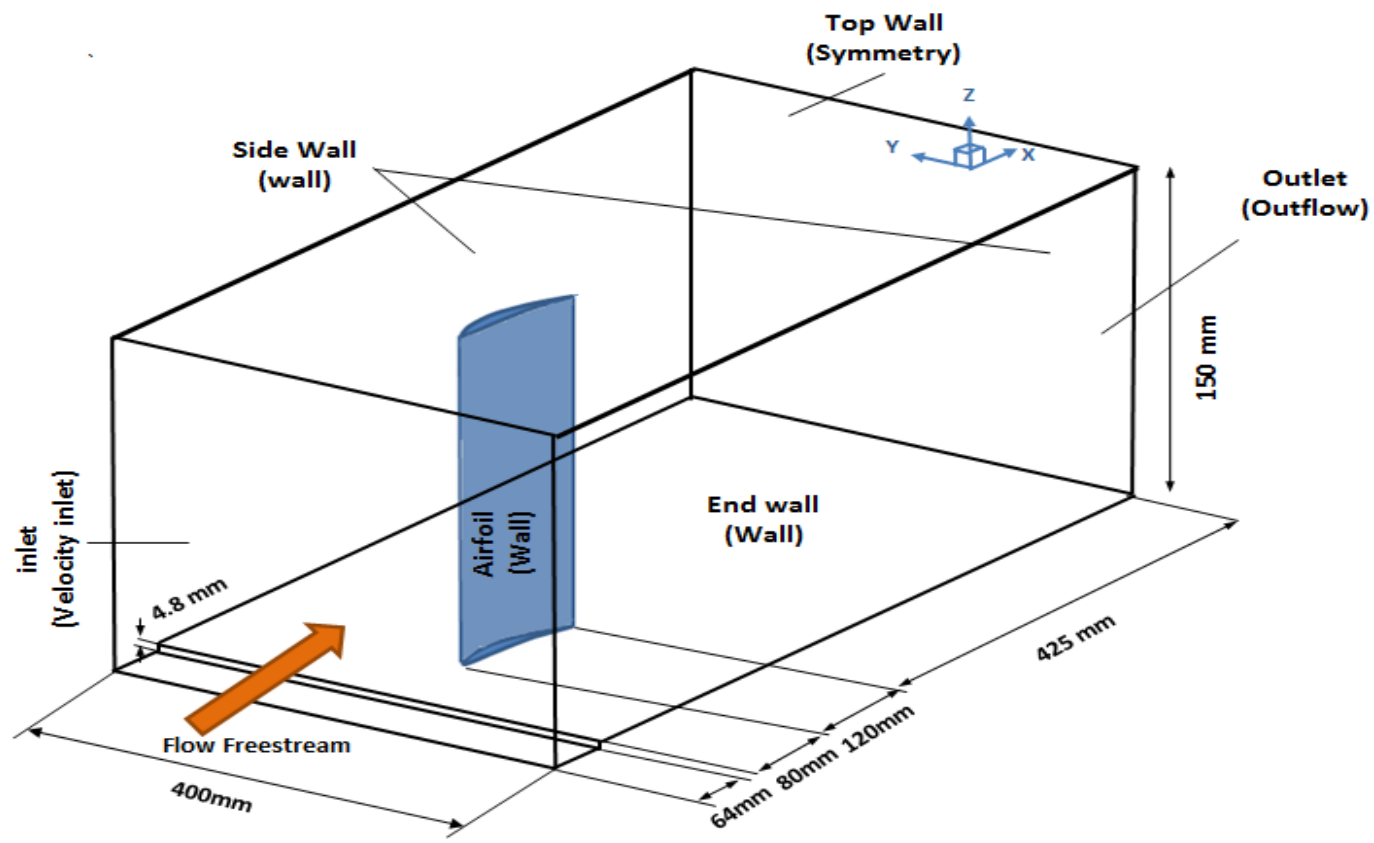

Gbr 1. Domain Simulasi 


\section{HASIL DAN DISKUSI}

Akibat penambahan FFST pada bidang tumpu (endwall junction) mengakibatkan terjadinya perubahan karakteristik pada aliran secara signifikan. Hal ini sesuai dengan Sutrisno [9] dan didukung oleh Mirmanto [6] Analisa dilakukan di daerah dekat dinding (bidang tumpu) untuk mengetahui perubahan karakteristik aliran di depan Leading edge dan belakang trailing edge dengan dan tanpa menggunakan FFST dengan variasi Angle of attack (AoA) sehingga diperoleh data sebagai berikut:

\section{Karakteristik Aliran Pada Lower Side}

Karakteristik aliran pada proses awal terbentuknya separasi aliran 3D akibat penambahan FFST sedikit berbeda apabila di bandingkan dengan pada pelat datar. Pada pelat datar posisi end stagnation point lebih mendekati endwall, karena aliran dari inlet memiliki momentum yang masih kuat, sehingga aliran lebih mampu menekan akhir stagnasi. Sedangkan pada penambahan FFST, posisi end stagnation point lebih menjauhi endwal, hal ini terjadi karena profil kecepatan dalam boundary layer masih belum berkembang setelah melewati FFST, akibatnya aliran tersebut memiliki momentum yang masih lemah sehingga aliran tersebut memiliki akhir stagnasi yang lebih jauh dari endwall. Perbedaan posisi end stagnation point berdampak signifikan terhadap posisi forward saddle point (FSP). Akibat penambahan FFST posisi FSP lebih menjauhi body bila di bandingkan tanpa penambahan FFST.
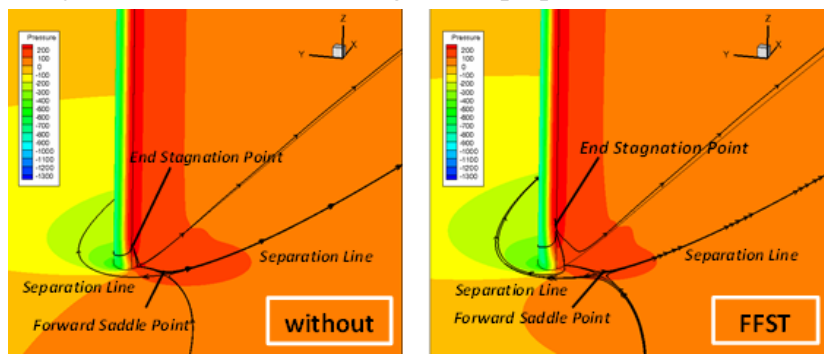

Gbr 3. Posisi End Stagnation Point dengan dan Tanpa FFST $\left(\alpha=8^{\circ}\right)$

Separasi aliran 3D di tandai dengan terbentuknya forward saddle point. Diketahui FSP bercabang menjadi dua aliran utama berupa garis separasi 3D yang bergerak menyusuri upper side dan lower side pada body endwall junction, serta bergerak berlawanan arah inlet menuju trailing edge.

\section{Karakteristik Aliran Pada Upper Side}

Akibat penambahan FFST separation line 3D lebih mampu meneruskan perjalananya hingga ke downstream. Attachment line di dalam formasi horseshoe vortex lebih mampu mengikuti kontur body, akibatnya aliran tersebut lebih mampu melawan friction dan adverse pressure, sehingga attachment line tersebut mampu attach terhadap curl flow dan membentuk backward saddle point yang lebih dekat terhadap trailing edge. Hal ini berbeda pada pelat datar, dimana separation line 3D tidak mampu meneruskan perjalanan hingga ke downstream namun terhenti pada tengah body airfoil seperti yang ditunjukkan pada gambar 4 .

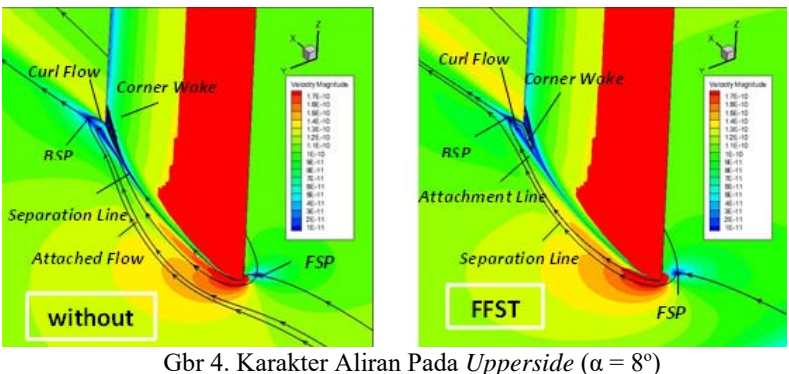

Gambar 5 menunjukkan visualisasi aliran berupa goresan shear stress line dengan dan tanpa penambahan FFST melalui kontur pathline secara 2D. Pada kontur pathline tampak jelas posisi FSP yang lebih menjauhi body akibat penambahan FFST. Separation line 3D di zona lower side juga terlihat membuka lebih lebar bila dibandingkan pada pelat datar. Namun terlihat jelas pada daerah upperside dengan penambahan FFST bentuk goresan shear stress line lebih mengikuti kontur body, serta blockage area akibat penambahana FFST dibelakang trailing edge lebih kecil bila dibandingkan pada plat datar.
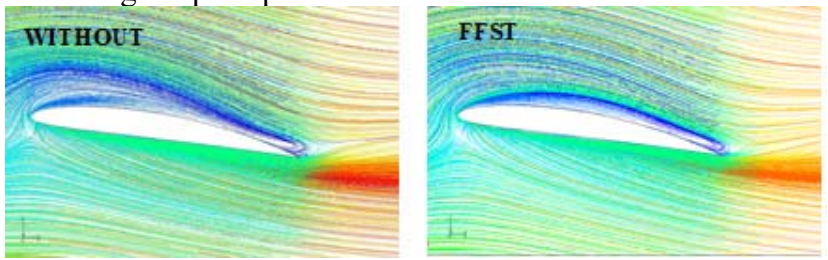

Gbr 5. Visualisasi Aliran dengan Menggunakan Kontur Pathline $\left(\alpha=8^{\circ}\right)$

Selain menggunakan metode melihat goresan shear stress line (visualisasi pathline) untuk dapat menganalisis karakteristik aliran 3D, perlu juga dilakukan analisa distribusi tekanan di daerah dekat dinding. Diketahui distribusi tekanan statis memegang peranan penting terhadap analisis medan aliran 3D di daerah interaksi antara endwall dengan bodi tunggal, dimana distribusi tekanan statis hasil eksperimen dinyatakan dalam koefisien tekanan $(\mathrm{Cp})$.

Berdasarkan gambar 6 secara global dapat dilihat degradasi kontur warna di sekitar body airfoil. Harga maksimum tekanan diperlihatkan oleh warna merah yang terletak sedikit di bawah leading edge. Hal ini mengindikasikan pada daerah ini aliran dihentikan secara mendadak, selanjutnya akan terbentuk local stagnation pressure dengan harga coeffisien pressure $(\mathrm{Cp})$ yang lebih besar dari harga di sekitarnya. Namun apabila dibandingkan dengan titik stagnasi 2D pada mid span, harga $\mathrm{Cp}$ tersebut jauh lebih kecil.

Pada zona lower side didominasi oleh tekanan tinggi, ketika aliran bergerak semakin menuju trailing edge, daerah bertekanan tinggi semakin berkurang. Namun akibat penambahan FFST diketahui bahwa tekanan di zona lower side semakin berkurang, akibatnya antara upper dan lower side di trailing edge memiliki nilai perbedaan tekanan yang tidak terlalu besar bila dibandingkan pada pelat datar (tanpa FFST), hal ini mengakibatkan curl flow yang terbentuk lebih lemah sehingga aliran lebih mampu meneruskan perjalanannya ke downstream. 


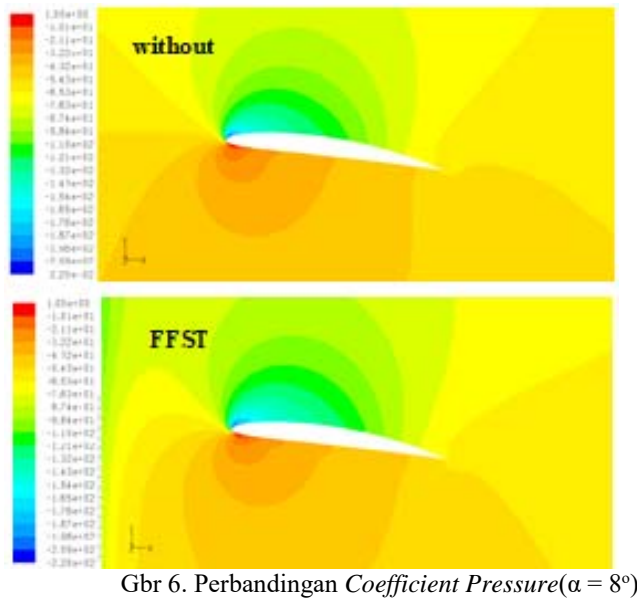

Secara global pada upper side di perlihatkan warna hijau hingga kebiruan, hal ini berarti tekanan di daerah upper side rendah terutama pada daerah di atas leading edge. Selanjutnya diketahui akibat penambahan FFST membuat tekanan rendah di daerah upper side semakin menuju ke belakang hingga mendekati trailing edge, hal ini berarti bahwa akibat penambahan FFST menyebabkan peningkatan intensitas turbulensi yang berubah menjadi momentum. Dengan perubahan momentum aliran berenergi lebih besar tersebut, akibatnya aliran lebih mampu mengatasi kerugian tekanan (adverse pressure) dan garis separasi lebih kebelakang yang mengakibatkan wake lebih kecil.

Fenomena terjadinya separasi aliran 3D pada aliran yang melintasi daerah upper side yang dekat endwall akan dipertegas oleh distribusi vektor kecepatan pada bidang $\mathrm{X}-\mathrm{Z}$ seperti yang di tunjukkan pada gambar 7 .

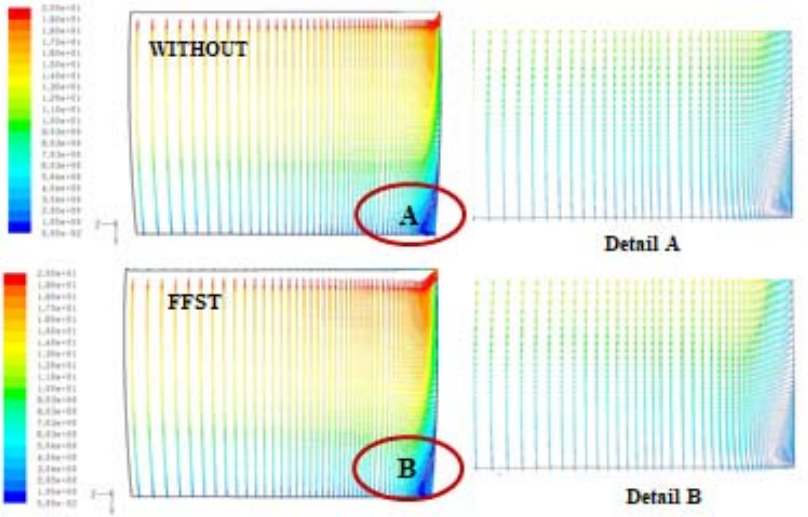

Gbr 7. Vektor Kecepatan (a) FFST dan (b) Tanpa Penambahan FFST

Akibat penambahan FFST dan tanpa penambahan FFST pada upper side body. Secara global pada sisi trailing edge (dekat endwall) memiliki vektor kecepatan yang lebih rendah ditunjukkan dengan warna biru dan garis vektor yang semakin kecil, serta diketahui arah vektor melintang di pojok trailing edge dan membuat blockage terhadap aliran utama. Hal ini mengindikasikan bahwa kecepatan aliran viscous pada permukaan upper side dekat trailling edge dan endwall sangat rendah serta aliran rendah tersebut membentuk vortex. Akibat penambahan FFST kecepatan rendah pada sisi trailing edge lebih sedkit bila di bandingkan tanpa penambahan FFST yang cenderung lebih di dominasi oleh kecepatan rendah, hal ini berarti dengan penambahan FFST aliran lebih mampu mengatasi adverse pressure di daerah trailing edge serta terlihat pula corner wake yang terbentuk di daerah pojok antara upper side dengan endwall yang hanya meliputi luasan relatif sempit.

\section{Kerugian Energi di Daerah Dekat Dinding}

Telah diketahui separasi aliran 3D menyebabkan penyumbatan aliran dan penurunan tekanan, pada kondisi ini kerugian energi di daerah separasi dapat dimodelkan dalam bentuk grafik axial total pressure loss coefficient $\left(\zeta_{\mathrm{v}}\right)$.
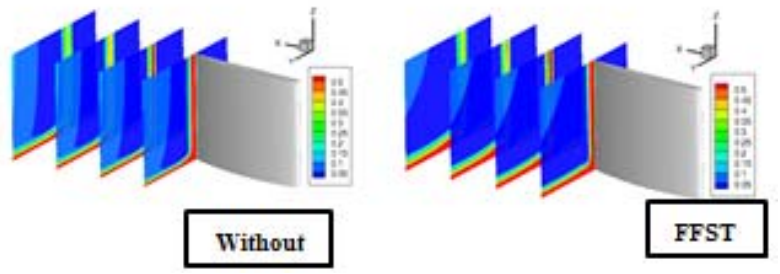

Gbr 8. Perbandingan distribusi axial total loss

Secara global daerah yang dekat dengan body tepat di belakang trailing edge memiliki harga total preesure loss yang lebih besar terutama di daerah dekat dinding, namun harga tersebut berangsur-angsur semakin berkurang seiring dengan semakin jauhnya posisi aliran terhadap daerah separasi. Nilai axial total pressure loss coefficient menunjukkan kerugian energi yang berupa turunnya tekanan di lokasi tersebut. Untuk lebih memperjelas harga axial total pressure loss coefficient di belakang trailing edge, maka akan di sajikan pengambilan gambar $6 \mathrm{~cm}$ dibelakang trailing edge.
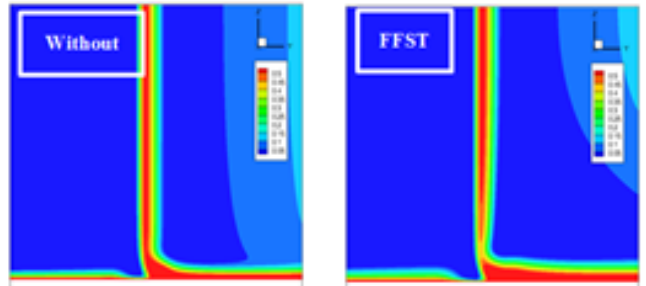

Gbr 9. Perbandingan Distribusi Axial total pressure loss Pada Jarak $6 \mathrm{~cm}$ dibelakang Trailing Edge $\left(\alpha=8^{0}\right)$

Gambar 9 menunjukkan harga axial total pressure loss pada jarak $6 \mathrm{~cm}$ di belakang trailing edge, diketahui bahwa pada pelat datar harga axial total pressure loss lebih menguasai bila di bandingkan dengan adanya penambahan FFST yang memiliki daerah dengan axial total pressure loss yang cenderung lebih sempit. Diketahui total pressure pada jarak $6 \mathrm{~cm}$ di belakang trailing edge pada pelat datar sebesar $195 \mathrm{~Pa}$ sedangkan dengan penambahan FFST sebesar $198 \mathrm{~Pa}$. Berdasarkan nilai tersebut dapat diketahui bahwa penambahan FFST membuat total pressure lebih besar di belakang trailing edge. Nilai axial total pressure loss pada pelat datar dan 
penambahan FFST masin-masing sebesar 0.209 dan 0.195, serta dengan penambahan FFST pada angle of attach $8^{0}$ mampu mereduksi total pressure loss sebesar 7,36 \%.
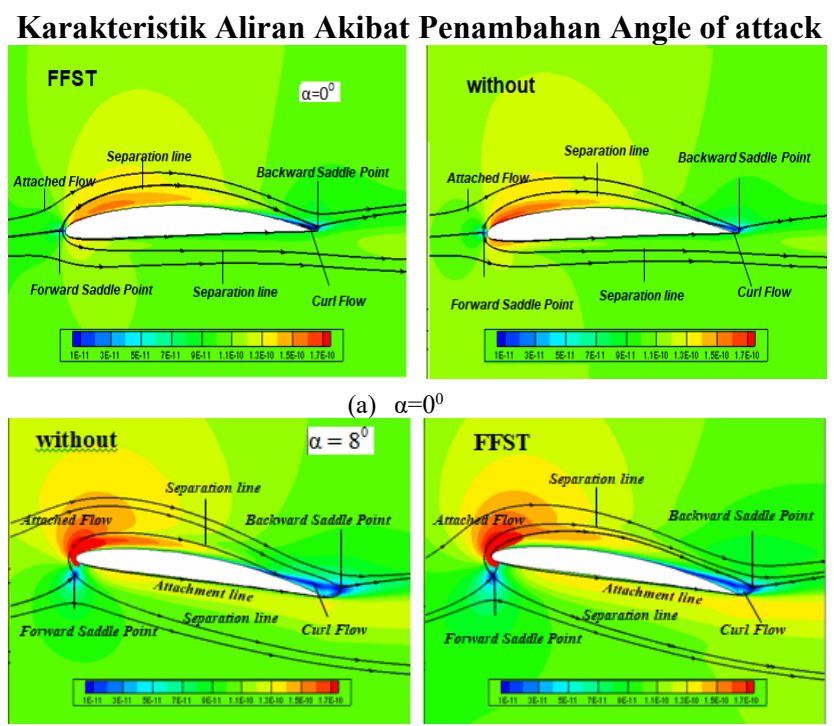

(b) $\alpha=8^{0}$

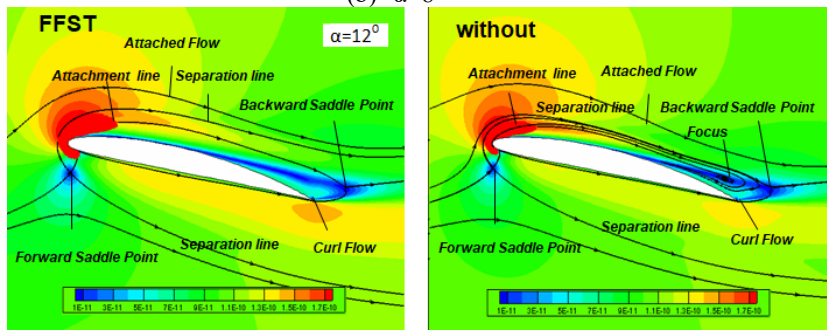

(c) $\alpha=12^{0}$
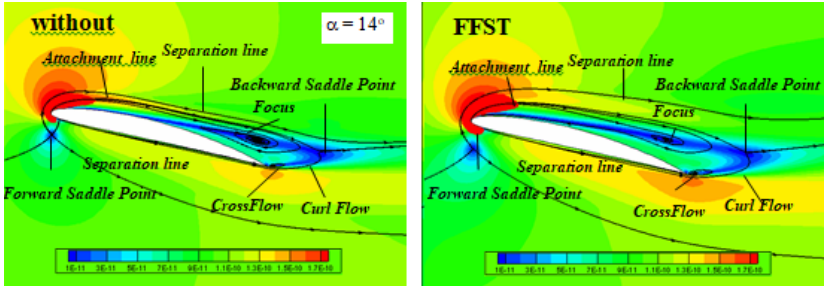

(d) $\alpha=14^{0}$
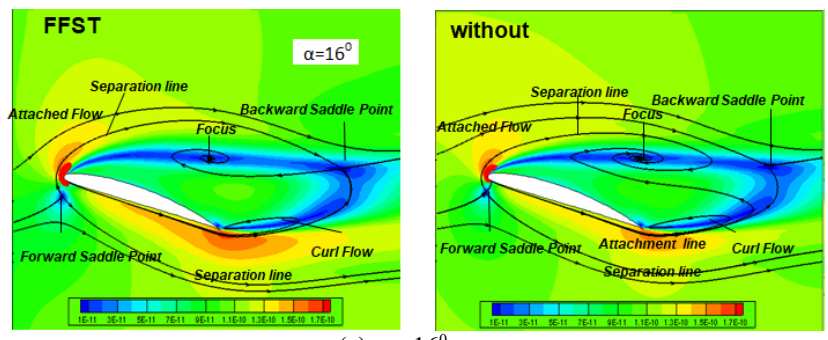

(e) $\alpha=16^{0}$

Gbr 10. Visualisasi Aliran Dengan dan Tanpa Penambahan FFST pada (a) $\alpha=0^{\circ}$, (b) $\alpha=8^{\circ}$, (c) $\alpha=12^{\circ}$, (d) $\alpha=14^{\circ}$ dan (e) $\alpha=16^{\circ}$
Secara global akibat peningkatan angle of attack (AoA) seperti yang ditunjukkan pada gambar 10. Goresan skin friction line pada permukaan endwall membuat stream tube semakin membuka lebar. Peningkatan angle of attack (AoA) menyebabkan aliran pada upper side akan mengalami lintasan yang lebih panjang dibandingkan dengan daerah lower side. Sehingga aliran pada upper side akan dipaksa untuk melalui daerah percepatan (sharply accelerate) dan membutuhkan energi yang lebih besar. Sedangkan pada daerah lower side juga dibutuhkan energi yang besar, hal ini dikarenakan aliran harus melintasi daerah bertekanan tinggi akibat peningkatan angle of attack (AoA). Dengan demikian dapat disimpulkan bahwa akibat peningkatan angle of attack (AoA) membuat struktur shear stress lines pada upstream terlihat lebih membuka, hal ini akan diikuti dengan semakin lebarnya wake di daerah downstream.

Backward saddle point merupakan singular point yang terjadi akibat bertemunya attachment line yang mengikuti kontur body dengan curl flow, backward saddle point merupakan tanda terjadinya separasi airan di belakang trailing edge. Berdasarkan gambar 10 dapat diketahui bahwa akibat peningkatan angle of attack (AoA) posisi backward saddle point semakin menjauhi trailing edge serta percabangan separation line 3D dari backward saddle point yang menuju upstream semakin kuat sehingga blockage area semakin luas.

Tabel 1 attachment line yang membentuk BSP di downstream
\begin{tabular}{|c|c|c|}
\hline Sudut & Without & FFST \\
\hline 0 & Attached flow & Attachment line \\
\hline 8 & Attached flow & Attachment line \\
\hline 12 & Separation line $3 D$ & Attachment line \\
\hline 14 & Attachment line & Attachment line \\
\hline 16 & Attached flow & Separation line $3 D$ \\
\hline
\end{tabular}

Berdasarkan tabel 1 akibat peningkatan angle of attack (AoA) aliran mampu memperbaiki karakteristik alirannya sendiri, hal ini terlihat dari jenis pertemuan attachment line dengan curl flow yang membentuk backward saddle point. Dengan meningkatnya angle of attack (AoA) pada pelat datar akan semakin memperkuat curl flow dan akan membuat aliran didalam formasi horseshoe vortex sulit menuju downstream, sehingga aliran tersebut mudah terinduksi oleh attached flow di luar formasi horseshoe vortex. Sedangkan akibat penambahan FFST mampu memperlemah curl flow bila dibandingkan dengan pelat datar, serta separation line $3 D$ lebih mampu menuju downstream dan attachment line di dalam formasi horseshoe vortex mampu bertemu curl flow untuk membentuk backward saddle point.

Berdasarkan tabel 2, dapat diketahui bahwa akibat peningkatan angle of attack (AoA) baik dengan dan tanpa FFST nilai total pressure memiliki track menurun. Namun akibat penambahan FFST, nilai axial total pressure loss lebih kecil bila dibandingkan tanpa penambahan FFST, dan meningkat seiring dengan bertambahnya angle of attack (AoA). 
Tabel 2. Kerugian Energi Akibat Peningkatan Angle of attack (AoA)

\begin{tabular}{|c|c|c|c|c|}
\hline \multirow{2}{*}{ Sudut } & \multirow{2}{*}{ Treatment } & \multirow{3}{*}{$\begin{array}{c}\text { Total Pressure (Pa) } \\
\text { ( } 6 \mathrm{~cm} \text { di belakang } \\
\text { TE) }\end{array}$} & \multicolumn{2}{|c|}{$\begin{array}{l}\text { Axial Total Pressure } \\
\text { Loss } \zeta_{v}(\mathrm{~Pa})\end{array}$} \\
\hline & & & $\begin{array}{c}(6 \mathrm{~cm} \mathrm{di} \\
\text { belakang TE) }\end{array}$ & $\begin{array}{c}\% \\
\text { Reduksi }\end{array}$ \\
\hline \multirow{2}{*}{$\mathbf{0}$} & FFST & & 0,164 & \multirow{2}{*}{4,81} \\
\hline & WITHOUT & 203 & 0,172 & \\
\hline \multirow{2}{*}{8} & FFST & 198 & 0,195 & \multirow{2}{*}{7,36} \\
\hline & WITHOUT & 195 & 0,209 & \\
\hline \multirow{2}{*}{12} & FFST & 179 & 0,275 & \multirow{2}{*}{4,64} \\
\hline & WITHOUT & 175 & 0,288 & \\
\hline \multirow{2}{*}{14} & FFST & 161 & 0,350 & \multirow{2}{*}{1,10} \\
\hline & WITHOUT & 159 & 0,354 & \\
\hline \multirow{2}{*}{16} & FFST & 132 & 0,472 & \multirow{2}{*}{2,05} \\
\hline & WITHOUT & 130 & 0,482 & \\
\hline
\end{tabular}

Efektifitas penambahan FFST pada bidang tumpu Airfoil Asimetri British 9C7/22.5C50 paling besar terjadi pada angle of attack (AoA) $8^{\circ}$, yaitu sebesar $\mathbf{7 , 3 6} \%$ kerugian energi ke arah axial dan efektifitas penambahan FFST terkecil pada angle of attack (AoA) $14^{\circ}$ sebesar 1,10 \%. Hal ini sedikit berbeda jika mengacu pada referensi [8] jika diterapkan pada airfoil asimetri british pada chamber kuat.

\section{KESIMPULAN}

Berdasarkan hasil simulasi numerik terkait Separasi Aliran 3D akibat penambahan FFST pada bidang tumpu Airfoil Asimetri British 9C7/22.5C50 dengan Variasi angle of attack (AoA) sebesar $0^{0}, 8^{0}, 12^{0}, 14^{0}, 16^{0}$, dapat di simpulkan bahwa :

a. Penambahan FFST menyebabkan posisi FSP lebih menjauhi body akibat perubahan posisi end stagnation point lebih menjauhi endwal.

b. Perubahan posisi FSP akibat penambahan FFST mengakibatkan intensitas turbulensi aliran di dekat dinding menjadi momentum, akibatnya aliran lebih mampu mengatasi kerugian tekanan (adverse pressure) dan garis separasi lebih kebelakang yang mengakibatkan wake lebih kecil.

c. intensitas curl flow lebih kecil serta blockage area lebih sempit akibat posisi backward saddle point lebih mendekat ke trailing edge.

d. Peningkatan angle of attack (AoA) menyebabkan:

$\checkmark$ Struktur garis tegangan geser (shear stress lines) pada upstream lebih membuka, sehingga membuat wake lebih membuka di daerah downstream.

$\checkmark$ Posisi forward saddle point lebih mengarah ke lower side

$\checkmark$ Posisi BSP semakin menjauhi trailing edge yang menyebabkan blockage area semakin luas. $\checkmark$ Penguatan curl flow pada trailing edge

$\checkmark$ Aliran mampu memperbaiki karakteristik alirannya sendiri

$\checkmark$ Nilai total pressure loss semakin meningkat seiring dengan peningkatan angle of attack (AoA).

e. Efektifitas penambahan FFST paling besar terjadi pada angle of attack $8^{\circ}$

\section{UCAPAN TERIMA KASIH}

Penulis sampaikan terimakasih kepada semua pihak yang telah membantu proses pengambilan data, pengolahan data, bimbingan, masukan dan kontribusinya sehingga tulisan ini terwujud.

\section{REFERENSI}

[1] Horlock, J.H., dan Lakshminarayana, B., Leakage and Secondary Flows in Compressor Cascades, Ministry of Tecnology Aeronautical. Research Council Report and Memoranda, No. 3483. 1987.

[2] Mirmanto, H. dan Sasongko, H.”Reduksi Kerugian Sekunder Melalui Penambahan Leading Edge Fairing". Jurnal Teknik Mesin. Volume 9 Nomor 2: 105-114. 2009

[3] Abdulla, A.K., Bhargava, R.K. dan Raj,R. An Experimental Study of Local Wall Shear Stress, Surface Static Pressure, and Flow Visualization Upstream, Alongside and Downstream of a Blade Enwall Corner. ASME Paper no. 90-GT-356. 1991

[4] Nugroho, G. Dan Ikhwan, N. Permodelan Turbulensi dalam Simulasi Aliran Sekunder pada Kaskade Kompressor Aksial dengan Stagger Lemah dan Variasi Tip-Clearance. Jurnal Teknik Mesin Volume 5 Nomor 2. 2005.

[5] Sherry, M.J, Jacono, D.L and Sheridan, J., "Flow Separation Characterisation of a Forward Facing Step Immersed in a Turbulent Boundary Layer". Sixth International Symposium on Turbulence and Shear Flow Phenomena. pp. 1325-1330. 2009.

[6] Mirmanto, H., Sutrisno., Sasongko, H dan Noor, DZ.. Reduction of Energy Losses in the Endwall Junction Area Through the Addition of Forward Facing Step Turbulent Generator. Applied Mechanics and Materials Vol. 493 (2014) pp 256-261. 2014.

[7] Nurjannah, Ika. Mirmanto, H. Sasongko, H. "Studi Karakteristik Separasi Aliran 3D pada Bidang Tumpu Airfoil Asimetri British 9C7/22.5C50 dengan Penambahan Forward Facing Step Turbulator (FFST)". Prosiding Seminar Nasional Pascasarjana XIV - ITS. ISBN 978-602-96565-7-2. Hal 486. Agustus. 2014.

[8] Rohmawati, Iis. Sasongko, H. Mirmanto, H. Nurjannah, Ika. "Studi Karakteristik Separasi Aliran 3D Melintasi Bidang Tumpu Airfoil Asimetri Camber Kuat dengan Penambahan Forward Facing Step Turbulator (FFST), Studi Kasus Airfoil British 9C7/42.5C50". Prosiding Seminar Nasional Pascasarjana XIV - ITS ISBN 978-602-96565-7-2. Hal. 480. Agustus .2014.

[9] Sutrisno. Mirmanto, H dan Sasongko, H. "Studi simulasi numerik struktur aliran sekunder akibat variasi posisi Forward Facing Step Turbulent Generator disekitar bidang tumpu pada bodi simetris". Scientific Repository. [Online], https://core.ac.uk/reader/32452949 